\title{
La Lingüística Cuir en diálogo con los Estudios Críticos de Discapacidad en Latinoamérica. Un estudio de caso de la prensa colombiana
}

\section{Queer Linguistics in Dialogue with Critical Disability Studies in Latin America. A Case Study of the Colombian Press ${ }^{1}$}

Recibido: 10 de diciembre

de 2019

Aceptado: 2 de septiembre de 2020

Publicado: 26 de julio 2021

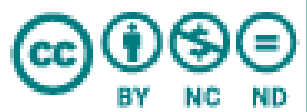

\section{David Leonardo García León ${ }^{1 *}$ Javier Enrique García León²}

1*Maynooth University, Maynooth, Irlanda. email: david.garcialeon@mu.ie

Dhttps://orcid.org/0000-0003-2360-5603

${ }^{2}$ University of North Carolina at Charlotte, Charlotte, Estados Unidos. email: javier.garcialeon@uncc.edu, (D) https://orcid.org/oooo-0oo3-3477-3346

*Autor para correspondencia

\section{Resumen}

Este artículo tiene por objetivo presentar los desarrollos de la Lingüística Queer (LQ) y examinar sus potencialidades en el estudio de la representación de minorías sexuales y de género en la industria mediática latinoamericana de habla española. En particular, dichas potencialidades se fundamentan en relacionar la LQ con los estudios críticos de la discapacidad. Para lograr este objetivo, se presenta un estudio de caso de la representación de

CÓMO CITAR: García, David y García, Javier. (2021). La Lingüística Cuir en diálogo con los Estudios Críticos de Discapacidad en Latinoamérica. Un estudio de caso de la prensa colombiana. Revista Interdisciplinaria de Estudios de Género de El Colegio de México, \%, e560. doi: http://dx.doi.org/10.24201/reg.v7i1.560

\footnotetext{
${ }^{1}$ Ambos autores contribuyeron de manera equitativa en la elaboración de este trabajo.
} 
una mujer trans discapacitada en la prensa escrita y audiovisual colombiana. El análisis evidencia que la prensa individualiza el devenir trans discapacitado y oculta las causas, los agentes, la discriminación y la precarización productoras del debilitamiento de estas subjetividades. De este modo, se propone una lingüística cuir interseccional, crítica y decolonial que aporte al estudio de la construcción discursiva de la cisheteronormatividad y sus interseccionalidades, especialmente aquellas que se articulan con la corporalidad y la discapacidad.

Palabras clave: transgénero; discapacidad; prensa colombiana; lingüística queer; discurso multimodal.

\begin{abstract}
This article presents the main principles of queer linguistics (QL) and examines their potential in the study of how the Latin American Spanish-language media industry portrays sexual and gender minorities. In particular, the authors explore these potentialities by making a connection between QL and critical disability studies, presenting a case study of the Colombian media's representation of a disabled transgender woman. The analysis shows that the media individualizes trans-disabled experiences and hides the causes and agents that undermine, discriminate, and jeopardize these subjectivities. Therefore, this QL-based intersectional, critical and de-colonial approach contributes to research into the discursive construction of cisheteronormativity and its intersectionalities, especially those connected to corporality and disability.
\end{abstract}

Keywords: transgender; disability; Colombian media; queer linguistics; multimodal discourse. 


\section{Introducción}

La Lingüística Queer (LQ) es una de las principales disciplinas encargadas del estudio de la construcción discursiva de la heteronormatividad y del binarismo de género. Este enfoque se ha desarrollado desde finales de los años 90 como una herramienta para el estudio del discurso y su relación con los asuntos de género, ya que combina perspectivas metodológicas del análisis crítico del discurso, la lingüística de corpus y el análisis multimodal del discurso con la teoría queer. La LQ ha tenido un fuerte auge en el norte global, de ella se resaltan trabajos que exploran la representación de las personas transgénero en la prensa del Reino Unido y Estados Unidos (Baker, 2014; Zottola, 2018; Ferraresi, 2018) y la construcción de la identidad lingüística en el cine queer anglosajón (Motschenbacher, 2010) entre otros estudios. En el sur global, Brasil y Sudáfrica son, posiblemente, los países que poseen más investigaciones desde este enfoque. Para el caso brasilero se destacan trabajos sobre las representaciones mediáticas brasileñas del cuerpo masculino (Borba y Milani, 2019); las prácticas lingüísticas de personas bisexuales en Brasil (E. Lewis, 2013; 2018) y los discursos sobre identidades homoeróticas masculinas en aplicaciones de citas (Maués Corrêa y da Silva Cruz, 2019). También es importante mencionar el libro Dissidências sexuais e de gênero nos estudos do discurso (Pereira, 2017), especialmente la contribución de Ismar Inácio dos Santos sobre $\mathrm{LQ}^{2}$. En el caso sudafricano, las investigaciones han girado en torno a los discursos multimodales sobre el espacio y la sexualidad en las universidades de ese país (Milani, 2013b) y la relación entre identidad y lengua en sitios web sudafricanos diseñados para hombres gais (Milani, 2013a), entre otros.

Sin embargo, en los países de habla hispana, la LQ es poco conocida y no pertenece a los enfoques de investigación más usados en el campo de los estudios del lenguaje. Una exploración de los resúmenes y actas de reconocidos congresos, — como los de la Asociación de Lingüística y Filología de América Latina $(2011,2014,2017)$ y la Asociación

\footnotetext{
${ }^{2}$ Cabe destacar que dos trabajos recientes (Borba, 2015; Lau y Borba, 2019) han tenido por objetivo dar a conocer, en el contexto académico brasilero, los principios y las discusiones actuales de la LQ. Del mismo modo, la Asociación Brasileña de Lingüística, a través del ciclo de conferencias virtuales ABRALIN ao vivo Linguists Online 2020, organizó una mesa sobre lingüística aplicada queer el 28 de mayo de 2020.
} 
Latinoamericana de Estudios del Discurso $(2015,2017)$ al igual que sus respectivas revistas, Lingüística y Revista Latinoamericana de Estudios del Discurso (2003-2019)_, indican que la LQ no es una de las líneas de estudio más utilizadas en la lingüística hispánica de la región. Existen, no obstante, tres estudios que combinan la LQ con los estudios culturales de representación. En ellos se examina la representación de las personas transgénero en la prensa de Colombia y Venezuela (J.E. García León, 2021); la representación de las masculinidades normativas y no normativas en las revistas para hombres producidas en Colombia (D.L. García León, 2018a) y la construcción discursiva de la intersexualidad en la jurisprudencia colombiana (García León y García León, 2017)³.

Adicionalmente, la LQ posee un carácter interseccional, pues su objetivo es entender la forma en que la construcción discursiva de la heteronormatividad está atravesada por aspectos como la clase, la raza, y la corporalidad (Leap, 2015). Sin embargo, son pocas o nulas las investigaciones donde la LQ dialoga con los estudios críticos de discapacidad (ECD) en el contexto Latinoamericano. Esto sucede a pesar de que en las últimas dos décadas la teoría queer ha dialogado con estos estudios; piénsese, por ejemplo, en el reconocido trabajo de Robert McRuer (2006) Crip Theory: Cultural Signs of Queerness and Disability y en los diferentes conceptos que ambas disciplinas comparten y han desarrollado (por ejemplo, tiempo crip y tiempo queer). De este modo, es necesario pensar cómo la LQ puede beneficiarse de los ECD desde y para Latinoamérica.

Por lo tanto, el presente trabajo tiene un doble objetivo. Primero, presentar los desarrollos de la LQ y examinar sus potencialidades para el estudio de diversos asuntos en Latinoamérica desde una mirada crítica y decolonial, en especial en los países de habla española; en segundo lugar, presentar las potencialidades que desde los ECD dialogarían con la LQ. Para lograr este último objetivo, se presenta un estudio de caso discursivo multimodal queer crip en el que se analiza cualitativamente la representación de una mujer trans discapacitada. En específico,

\footnotetext{
${ }^{3}$ No se puede desconocer que existen múltiples estudios sobre asuntos de género desde el análisis crítico del discurso, en el mundo hispano, que se encuentran en diversas revistas académicas; sin embargo, éstos no se inscriben directamente dentro de la LQ. En España, se destaca el trabajo de José Javier Moreno Sánchez (2018; 2019).
} 
se explora la nota periodística Ammarantha Wass: activista, trans y ciega producida por el periódico colombiano El Espectador (2017).

\section{Una LQ crítica, decolonial e interseccional desde y para Latinoamérica}

La LQ explora, desde el posestructuralismo, la relación entre lengua, género y sexualidad. Dado que su propósito central es cuestionar la heteronormatividad y su mecanismo estabilizador (el binarismo de género), la LQ puede ser descrita como un tipo de investigación crítica desde un punto de vista lingüístico (Motschenbacher, 2010; Borba 2015; E. Lewis 2013). Adicionalmente y a diferencia de estudios primarios en relación con la sexualidad y el género, donde el centro de las investigaciones era el habla y la identidad de personas gais y lesbianas, la LQ se enfoca en todas las identidades sexuales y en los regímenes discursivos que las conforman. Esto significa que no sólo incluye el estudio de la heteronormatividad, sino también de la cisnormatividad además de otros sistemas de opresión ligados al género, el deseo y la sexualidad. La LQ ha optado por incorporar en sus preceptos teóricos el pensamiento queer, en especial, aquel que busca deconstruir los binarismos masculino/femenino, heterosexual/homosexual, cisgénero/transgénero. Cabe mencionar que, aunque en sus inicios la LQ se enfocaba en comprender los mecanismos lingüísticos que convierten a la heterosexualidad como la norma, ésta se ha expandido a explorar asuntos relacionados con la transexualidad y la intersexualidad.

Para la LQ, las identidades de género son problemáticas en tanto que regulan y producen la exclusión de aquellas personas que no se ajustan a las reglas sexo-genéricas (Motschenbacher, 2010). Por ello, la heteronormatividad se aborda desde el proceso de materialización discursiva, es decir, se entiende el discurso no como sinónimo de texto, sino como práctica que sistemáticamente forma el objeto al que se refiere, siguiendo a Foucault (1997). Del mismo modo que los enfoques constructivistas, la LQ concibe el género como un performance (hacer el género) y no como un hecho preestablecido ni natural a una corporalidad. La LQ, por lo tanto, sigue los preceptos de Butler (1990) quien considera que en las sociedades occidentales los cuerpos se instituyen por medio del lenguaje, es decir, éste 
les asigna una materialidad generizada. Como sostiene Motschenbacher: "Identifying people with gendered personal reference forms does not only construct them as gendered. It also functions as a normative imperative urging people to perform their identities in established ways - ways that Butler calls 'intelligible"' (2010, p.13).

Una tercera influencia es Jacques Derrida. La LQ asume el concepto de iterabilidad (iterability) como un elemento central para el estudio de la construcción discursiva de la cisheteronormatividad. Recuérdese que mientras que para Saussure (1983) el signo lingüístico tiene una conexión estable entre significante y significado que se rige por la convención social, Derrida restringe la iterabilidad al componente formal del signo lingüístico, el significante. El significado, por otra parte, no es estable y su relación con el significante depende del contexto y de los usos previos que se le otorga (Derrida, 1976). Por ello, Derrida propone el término de différance, un homófono del término francés différence, cuya escritura desviada o "incorrecta" indicaría que cada uso de las formas lingüísticas está destinado a ser una copia incompleta, nunca terminada, de los usos anteriores, dado que diferentes contextos producen sutiles cambios en el significado (Motschenbacher, 2010).

Bajo estas perspectivas posestructuralistas, la LQ cuestiona el esencialismo de las categorías identitarias sobre el género y cuestiona los discursos dominantes sobre la identidad. Cuestionar dicho esencialismo implica asumir una postura crítica; esto es, estudiar las experiencias localizadas de las personas dentro de las estructuras de poder que las sujetan. Por ello, la LQ parte de una postura crítica similar a la propuesta por el análisis crítico del discurso (ACD) (van Dijk, 1999; Wodak, 2006; Fairclough, 2003; Pardo, 2005; Resende, 2018) al explorar cómo el lenguaje permite u oculta las intersecciones de sexualidad, género, raza, clase y formas de injusticia social. La LQ, entonces, se interesa por entender la forma en que los presupuestos sobre la sexualidad (por ejemplo, sólo existen dos géneros, el masculino y el femenino) son aceptados como obvios, correctos, naturales y verdaderos y, si esta aceptación acrítica de estos mensajes coincide con condiciones y situaciones de jerarquía, exclusión y violencia hacia ciertos grupos sociales (por ejemplo, la comunidad trans) (Leap, 2015). 
Siguiendo a Teun van Dijk, el ACD se pregunta “CCómo son capaces los grupos dominantes de establecer, mantener y legitimar su poder y qué recursos discursivos se despliegan en dicho dominio?" (1999, p. 24). En el caso de la LQ, esta pregunta se centra en el estudio de la dominación que los discursos heteronormativos ejercen sobre un grupo social y en la forma en que se mantienen y legitiman en la esfera pública. Por ejemplo, el caso de la prensa, pues en ella las personas transgénero son objetivizadas, espectacularizadas y usadas para reestablecer el binarismo de género (Serrano, 2007; Baker, 2014; Zottola, 2018; J.E. García León, 2021). Estos procesos se realizan por medio de diversos recursos discursivos como el uso de estereotipos, la falta adecuada de fuentes de información y la nominación inadecuada, entre otros.

Un elemento que merece mayor discusión es la necesidad de decolonizar la LQ. Al igual que el ACD, la LQ debe optar por una perspectiva decolonial que permita el surgimiento de aportes teóricos y metodológicos propios desde y para los países latinoamericanos. En este sentido son importantes los aportes de Viviane de Melo Resende $(2018,2019)$ para quien decolonizar el ACD implica trabajar en tres áreas convergentes:

decolonizing knowledge, in the sense of criticizing theories and methods while understanding that there is no universal knowledge; decolonizing the power of the creative act of overcoming this universalizing knowledge, which means accepting the force of local methodological and theoretical production, especially by constantly questioning disciplinary separation and its impositions; and decolonizing the being, making strategic use of this paradoxical space, which contains the possibilities of knowledge communion, also including common knowledge (2018, p. 2).

En relación con la decolonización del saber y el poder, es importante anotar que la LQ toma esencialmente los principios de la teoría queer norteamericana y europea y, se olvida de los aportes que desde el sur global se han hecho al estudio de la sexualidad y el género. Este hecho no sólo concierne a la posición geográfica donde el conocimiento es producido, sino también a las lenguas en las que la producción académica se genera (principalmente inglés y 
francés). Este hecho perpetúa la supuesta universalidad del conocimiento producido en el norte y posiciona como local o simplemente regional al producido en el sur global ${ }^{4}$.

Si el objetivo es construir una LQ desde y para Latinoamérica, será necesario que ella se inscriba en los aportes de la teoría cuir. Es decir, desde una teoría que como su nombre españolizado indica busca "afirmarse y relocalizarse por medio de la reapropiación del estigma de hablar con 'acento' que pesa sobre las hablas castellanas y las coloca en una posición subalterna/defectuosa frente a la pronunciación 'correcta', (con acento anglófono), del término queer". (Valencia, 2014, p. 68). Cabe anotar que desde la adopción de la teoría queer han existido oponentes a partir del hispanismo de la región. Brad Epps (2008), por ejemplo, señala que la palabra queer no puede entenderse en español y por ende en América Latina. Su historia de reapropiación y resignificación (de insulto a orgullo) se pierde en el castellano. Además, otros investigadores e investigadoras de la región andina han propuesto la teoría $\operatorname{cuy}(r)$ en referencia al popular animal que habita en países como Ecuador y Colombia (Falconí, 2014). Esto implica que la teoría, y, por ende, la LQ conlleven la inflexión geopolítica decolonial de las periferias para desarticular la colonialidad del saber que se ha implantado desde lo queer blanco del primer mundo.

Implantar esta inflexión política decolonial involucra reconocer la existencia de una colonialidad del género. Ésta instaló nuevas jerarquizaciones sexuales en los territorios colonizados y modificó las relaciones locales en relación con la raza (Lugones, 2007; 2008). Este tipo de colonialidad aún genera efectos materiales en las condiciones de vida de millones de personas en el planeta y, con ayuda de los sistemas capitalistas, ha establecido como legítimas unas formas de concebir el género en oposición a otras vistas como locales y atrasadas. Ejemplo de lo anterior son las críticas que se han realizado a términos como transgénero, proveniente de Norteamérica (transgender), para referirse a múltiples subjetividades latinoamericanas. Este término esconde y excluye las realidades que viven muchas mujeres trans en la región, pues ellas prefieren el uso de términos como loca,

\footnotetext{
${ }^{4}$ Un aporte que busca cuestionar la dicotomía norte-sur es el libro Queering Paradigms IV. South-North Dialogues on Queer Epistemologies, Embodiments and Activisms (2014). 
transformista, travesti, muxe, entre otros (V. Lewis, 2010). Lawrence La Fountain-Stokes, en su intento por decolonizar el saber cuir latinoamericano, ha propuesto el concepto de transloca para loca-lizar estas subjetividades en el Caribe latinoamericano (2010). Este concepto es una desidentificación, en términos de José Esteban Muñoz (1999), que busca romper y crear nuevas alianzas y redefinir los significados y sensibilidades de lo trans desde Latinoamérica y el Caribe.

Para cerrar esta sección, es importante reflexionar sobre la relación entre la LQ/C y la perspectiva interseccional en el estudio de fenómenos lingüísticos y mediáticos. De acuerdo con Erez Levon (2015), la sociolingüística encargada del estudio de la lengua y su relación con el género se ha beneficiado de dialogar con la teoría interseccional. Se ha pasado de una perspectiva compartimentada, donde se analizaban de manera distintiva la raza, la clase, la etnia y el género, a una perspectiva interseccional que permite entender cómo las diferentes categorías se informan y constituyen entre sí. Aunque Levon se centra en la sociolingüística variacionista, son el ACD y la lingüística antropológica los que más han dialogado con la teoría interseccional. Borba y Milani, por ejemplo, proponen estudiar los discursos sobre las corporalidades brasileñas producidos por los medios desde una mirada interseccional que trate a los discursos mediáticos contemporáneos como "geological formations that carry the traces and colorations of the past that continue to be deeply meaningful in the present" (2019, p. 2).

Cabe mencionar que, a pesar de que existen estudios interseccionales desde la LQ/C como el caso brasileño señalado, la discapacidad continúa siendo una de las categorías relegadas en los trabajos sobre lengua, representación y sexualidad. Por ello, en los siguientes apartados se establecen las conexiones teóricas y metodológicas entre la LQ/C y los ECD y se expone un estudio de caso de la representación de una mujer trans discapacitada en la prensa colombiana. 


\section{LQ/C y la discapacidad crítica en diálogo interseccional}

La mayor parte de los estudios sobre la discapacidad y su representación mediática en Latinoamérica se realiza desde la perspectiva de los estudios literarios y culturales y, se ha centrado en países como México, Brasil y Argentina (Antebi, 2009; Antebi y Jörgensen, 2016) ${ }^{5}$. Aunque el ACD de habla hispana ha aportado algunos estudios - (Solves Almela, 2013; Vergara-Heidke y Torres-Calderón, 2019), una revisión de los contenidos, las perspectivas metodológicas y teóricas, y la bibliografía de los artículos publicados en reconocidas revistas como Discurso y Sociedad D\&S y la Revista Latinoamericana de Estudios del Discurso RALED - muestran que no se utiliza bibliografía especializada ni conceptos provenientes de los estudios de discapacidad, y mucho menos existen estudios que interseccionen dicha subjetividad con asuntos de género y sexualidad ${ }^{6}$.

No obstante, hay múltiples relaciones entre la LQ/C y los estudios de discapacidad. En primer lugar, ambas perspectivas se han enfocado en el estudio de la construcción discursiva de la corporalidad. La LQ/C, como sostuvimos, se centra en el estudio de la cisheteronormatividad y los efectos que el binarismo tiene sobre los cuerpos y los deseos y, su representación en la prensa. Por su parte, los estudios de discapacidad se han enfocado en los discursos dominantes que legitiman ciertas corporalidades y relegan otras de la esfera pública, es decir, se han centrado en esclarecer el funcionamiento de las sociedades capacitistas y sus efectos en la vida de las personas discapacitadas al igual que en la representación que se realiza de ellas ${ }^{7}$.

${ }^{5}$ En Norteamérica y Europa se han desarrollado diversos estudios de corte teórico y aplicado sobre la discapacidad y su representación. Desde los estudios culturales y literarios, se destacan los trabajos de Clare (1999; 2017); Fraser (2013); Garland-Thomson (2009); Gallop (2019); McRuer (2018); Snyder y Mitchell (2001); Shildrick (2009); Siebers (2010); Stamou et al. (2014). Desde el ACD, los trabajos más reconocidos son los de Jan Grue $(2011,2015)$ y Campos Pinto (2016). Por su parte el caso colombiano ha sido poco explorado, sólo existen algunos trabajos desde la perspectiva de los estudios culturales (Espinosa, 2016; Gutiérrez-Coba et al., 2017; Pardo Pedraza, 2017; D.L. García León, 2021; Rutter-Jensen, 2018).

${ }^{6}$ Los autores de este trabajo estamos realizando una investigación que aborda la representación de la discapacidad masculina heterosexual en el periodismo audiovisual colombiano desde la LQ/C, el análisis multimodal del discurso y los estudios críticos de discapacidad. Resultados preliminares de esta investigación fueron presentados en el 8th Language in the Media Conference: "Mediating Resistance" (D.L. García León, 2019).

${ }^{7}$ Por capacitista se entiende la discriminación y prejuicio social en contra de las personas con discapacidad. En este trabajo además se alternan las expresiones "en condición de discapacidad" y "persona/cuerpo/individuo 
La LQ deberá enfocarse en la manera como la norma, de manera más general, se constituye y naturaliza. Esto quiere decir que tendrá que examinar si las normas de género se fundamentan en nociones de capacidad y discapacidad. Según Eli Clare, "[a] woman who walks with crutches does not walk like a 'woman'; a man who uses a wheelchair and a ventilator does not move like a 'man'. The construction of gender depends not only upon the male and the female body, but also upon the nondisabled body" (1999, p. 128). La construcción relacional del género y la sexualidad ha sido poco explorada desde la LQ/C hispanoparlante, ésta merece un acercamiento profundo ya que permitiría comprender, por ejemplo, si las construcciones y figuras sociohistóricas generizadas (por ejemplo, la malinche, el macho latino, el don Juan) se fundamentan en representaciones e imaginarios vinculados a la (dis)capacidad. A la par, esto contribuiría a entender mejor los lazos que existen entre sexualidad y discapacidad que se evidencian en el uso de términos como "desviado", "enfermo", "anormal" para referirse y para mantener la discriminación tanto de personas en condición de discapacidad como de miembros de la comunidad LGBTI+. No se puede olvidar que al igual que el término queer, la palabra crip ha sido reapropiada por la comunidad discapacitada angloparlante para resemantizarla y usarla como discurso contrahegemónico, de resistencia y acción política (Kafer, 2013).

Asimismo, el cuerpo trans como el cuerpo discapacitado han sido constantemente vigilados, politizados y moldeados. Las representaciones de sus cuerpos se enmarcan en el paradigma que la cultura dominante occidental denomina como desviado. En los discursos hegemónicos, la discapacidad y la transgeneridad han sido construidas a través de figuras discursivas similares. Piénsese por ejemplo en los espectáculos de "anormales" (freak shows) en donde corporalidades sexo-genéricas no normativas convivían con subjetividades discapacitadas. Así, estas figuras contribuyen a mantener distinciones entre un nosotros y un ellos, en otras palabras, se fundamentan en construcciones culturales de la otredad a través de representar sus corporalidades como extraordinarias (Garland-Thompson, 1997).

discapacitado/a". Se evita términos capacitistas, opresivos y discriminatorios como "minusválido", "el/la discapacitado/a", "persona limitada", "(el/la) limitado/a" que han sido fuertemente cuestionados por activistas de la discapacidad. 
De igual manera, un aporte importante desde los ECD para LQ/C es revisar la potencialidad política de la sexualidad. La LQ/C ya ha cuestionado la manera en que lingüísticamente se constituye la homonormatividad; es decir, la forma como ciertos discursos se convierten en una versión 'homo' de la normalidad heterosexual históricamente establecida (Milani y Wolff, 2015). Además, se tendría que prestar atención a la manera como la construcción y la representación de la sexualidad discapacitada rompen o reproducen prácticas normativas del cuerpo, habilidades y deseos. Al explorar este tipo de sexualidad, nos enfrentamos a preguntas similares a las que se han hecho los activistas y teóricos queer, por ejemplo, si se está tratando de ganar acceso a la sexualidad dominante para las personas discapacitadas o si se está intentando modificar las maneras en que el sexo y la sexualidad son concebidas, expresadas y limitadas en las sociedades (pos)modernas actuales (Shakespeare, 2000). La LQ/C abogaría por esto último, esto es, por la ruptura de la norma desde una mirada que vincula como uno de sus ejes a la discapacidad.

Como bien señalamos, la $\mathrm{LQ} / \mathrm{C}$ en el contexto latinoamericano debe asumir una perspectiva decolonial frente al género, la sexualidad y el deseo. Dicho enfoque también deberá alimentarse de las discusiones en torno a la discapacidad. Al abordar la construcción discursiva de las masculinidades y feminidades (LGBTI+) latinoamericanas, no se debería obviar la manera como éstas han sido debilitadas y discapacitadas (física y mentalmente) por el legado colonial. No puede olvidarse que el sur Global es el lugar en donde el (neo)colonialismo ha generado más sujetos en condición de discapacidad a través de diversos mecanismos de violencia aún vigentes (por ejemplo, conflictos armados, ensayos nucleares y farmacológicos, exportación de polución y desechos) (Meekosha, 2011). Además, será necesario que las investigaciones en $\mathrm{LQ} / \mathrm{C}$ que dialogan con los ECD tengan en cuenta que: "as a field of knowledge, disability studies currently has the same global North focus as other fields of the human sciences. It too is in need of renovation by moving both empirically and conceptually to a world scale" (Connell, 2011, p. 1372). En otras palabras, la LQ/C deberá asumir una mirada interseccional estructural, en términos de Kimberle Crenshaw (1991), de la discapacidad, la sexualidad, el género y el deseo desde y para el sur. 
Esta geolocalización del saber cuir y discapacitado hace que nos preguntemos por el término crip y su traducción al español ${ }^{8}$. Como se mencionó, este concepto es la reapropiación de una injuria o agravio en el contexto norteamericano para reclamar la diferencia física desde un lugar legítimo. Paco Guzmán y Lucas Platero (2012) proponen que, para el caso del español, se piense más en los usos contextuales que en las traducciones literales de crip como tullido o impedido. Se podrían usar términos más frecuentes que forman parte de la cultura cotidiana de las personas con diversidad funcional como coja, tuerto, jorobado, etc. Marta Allué considera que existe una potencialidad en el uso del humor negro frente al estigma y como éste es una forma de reafirmación pública de una identidad atribuida (Allué citada en Guzmán y Platero, 2012). Además, este uso del humor podría tener potencialidades dialectales, es decir, abarcar las diversas variedades del español que existen en Latinoamérica.

Cabe anotar que varios activistas de la discapacidad de habla hispana han abogado por términos como diversidad funcional. Para ellos, discapacidad y discapacitado funcionan como conceptos paraguas que no permiten evidenciar los términos utilizados en contextos o naciones específicos, y desde el discurso médico se centran en la condición física. Además, estos términos se enfatizan completamente en el individuo o en la sociedad. Por esto, el uso de diversidad funcional busca ocupar un lugar intermedio, es decir, identificar corporalidades y funciones como diversas. En palabras de Romañach y Lobato, el término diversidad funcional "se ajusta a una realidad en la que una persona funciona de manera diferente o diversa de la mayoría de la sociedad. Este término considera la diferencia del individuo y la falta de respeto de las mayorías, que en sus procesos constructivos sociales y de entorno, no tiene en cuenta esa diversidad funcional" (2005, p. 4). Sin embargo, habría que mencionar que no existe consenso por parte de las personas funcionalmente diversas sobre el término de preferencia. Algunos activistas reivindican el término discapacidad, ya que es un mecanismo de apropiación del discurso médico que es resemantizado, generándose una lucha lingüística y simbólica con efectos reales sobre la comunidad discapacitada. Otros, por su

\footnotetext{
${ }^{8}$ Es importante reconocer que el español es una lengua dominante en relación con las numerosas lenguas indígenas, criollas, romanís y de señas habladas en Latinoamérica. Sin embargo, españolizar los términos ayuda a resignificar sus epistemologías norteamericanas y europeas desde una mirada local.
} 
parte, prefieren el término persona en condición de discapacidad, pues lingüísticamente esta expresión enfatiza a la persona y no a su condición médica.

Por otra parte, a nivel teórico la LQ/C puede dialogar con conceptos propuestos por los estudios de discapacidad y la teoría crip. A manera de ejemplo, se pueden explorar las potencialidades de dos conceptos: crip time (tiempo tullido) y debility (debilidad). El primero tiene dos acepciones, se refiere al tiempo adicional que las personas discapacitadas necesitan para llevar a cabo las tareas diarias de la vida (bañarse, vestirse, etcétera). Sin embargo, este tiempo adicional no debe entenderse simplemente como una consecuencia del cuerpo discapacitado, pues muchas veces las condiciones externas propias de las sociedades neoliberales capacitistas son las que producen o exacerban estos tiempos adicionales (Baril, 2016). El segundo significado del término alude a la manera en que esas mismas sociedades perciben el tiempo adicional como improductivo. En un sistema donde prima la eficacia y la productividad se evalúa a las personas discapacitadas de acuerdo con los parámetros de la temporalidad no discapacitada neoliberal, a través de términos como pérdida, desperdicio, gasto innecesario (Baril, 2016). No obstante, esta forma de entender el tiempo crip tiene una potencialidad, se puede comprender como un punto de fuga del sistema neoliberal actual, dado que existen personas que no viven bajo la temporalidad dominante de manera similar a lo que ocurre con las temporalidades queer. Cuando la LQ/C explora la construcción discursiva de la cisheteronormatividad podría centrarse en investigar cómo discursivamente se establecen temporalidades hegemónicas sobre la vida de ciertos individuos ya sean minorías sexuales y/o discapacitados.

Por su parte, el concepto de debilidad alude a los mecanismos biopolíticos generados por el neoliberalismo que desgastan lentamente algunas poblaciones sobre otras (Puar, 2017). Algunos cuerpos (por ejemplo, cuidadores migrantes de personas discapacitadas en países del "primer mundo") no son considerados como discapacitados o no se identifican a sí mismos como tal; sin embargo, están siendo constantemente debilitados por la falta de acceso a ciertos servicios sociales o por su posición en el mundo (el sur Global) (Puar, 2017). Adicionalmente, el concepto de debilidad evidencia aquellos aspectos que el término discapacidad no refleja debido a que este último se ha fundamentado en una perspectiva 
neoliberal de derechos. Para Jasbir Puar, la debilidad muestra la exclusión de ciertos cuerpos como un hecho endémico y no como algo excepcional y, más importante aún, evidencia la necesidad de repensar las estructuras sociales en vez de asumir una perspectiva de derechos que busca soluciones de acomodación (2017). Por lo tanto, debilidad y discapacidad dependen la una de la otra en las sociedades neoliberales actuales que se caracterizan por promover el empoderamiento de la discapacidad y por mantener la precariedad de ciertos cuerpos y poblaciones a través de desgastarlos, mutilarlos y ponerlos en constante riesgo (Puar, 2017).

En definitiva, estos dos conceptos deben ser loca-lizados en Latinoamérica pues no se puede olvidar que han sido producidos en el norte global para referirse a realidades que algunas veces no encajan perfectamente con las vividas en el Sur. El concepto de debilidad, por ejemplo, debe explorarse a partir de una mirada histórica que muestre cómo la colonización y la actual colonialidad neoliberal continúan debilitando los cuerpos latinoamericanos por medio de diversos tipos de explotación.

\section{La representación mediática de una mujer trans discapacitada: un estudio de caso en la prensa colombiana}

Antes de analizar la representación mediática de las personas trans discapacitadas en la prensa colombiana, es importante comprender la situación social de esta población. A la fecha, no existen datos específicos sobre el número de personas trans discapacitadas en Colombia, es decir, los datos existentes separan a estas dos poblaciones. En relación con la discapacidad, los más recientes estudios muestran que existen siete millones de personas en esta condición (Correa-Montoya y Castro-Martínez, 2016). Además, se calcula que el número de víctimas en condición de discapacidad producto del conflicto armado es de unas 344241 personas de un total de $8920473^{9}$. De acuerdo con Correa-Montoya y CastroMartínez (2016), aun a pesar de los esfuerzos gubernamentales producto de la Política

\footnotetext{
${ }^{9}$ Las cifras sobre las víctimas del conflicto armado son un estimado, pues muchas personas no se inscriben al Registro Único de Víctimas.
} 
Nacional de Discapacidad e Inclusión Social adoptada en 2013, la población colombiana discapacitada no puede vivir de manera autónoma y libre de violencia. Además de los estereotipos que circulan en el imaginario colectivo sobre la discapacidad, los gobiernos colombianos de las últimas décadas han implementado medidas neoliberales de austeridad que afectan de forma directa a grupos minoritarios, entre ellos a las personas discapacitadas. Estos gobiernos han llevado a cabo recortes en los servicios públicos y ceden la administración de los recursos a instituciones privadas, afectando el acceso a los servicios de salud, por ejemplo.

Por otra parte, la situación de las personas transgénero en Colombia no es alentadora. Las mujeres trans viven en condiciones de precariedad debido al limitado acceso a la educación, la salud y a un empleo formal (Colombia Diversa, 2017). Esta comunidad continúa sufriendo de violencia física y es una de las principales víctimas del conflicto armado en el país. En 2017, se reportaron 109 personas LGBTI+ asesinadas de las cuales 36 fueron mujeres y 3 hombres trans. Existe una relación clara entre la exclusión escolar, la falta de empleo y la violencia hacia estas personas pues "el 94\% de las personas trans asesinadas en 2017 sólo tenían estudios de educación básica primaria o secundaria, y el 63\% se dedicaban al trabajo sexual" (Colombia Diversa, 2017, p. 21). A este hecho se suma la persistente violencia que ejerce el Estado hacia estas personas, especialmente violencia policial. Por ejemplo, en 2017 se registraron 66 hechos violentos contra personas LGBTI+ de las cuales 31 fueron contra mujeres trans cuya edad promedio es de 24 años.

En lo concerniente al estudio de la representación de las personas trans discapacitadas en la prensa, a la fecha no fue posible rastrear estudios que exploren este fenómeno de manera interseccional. Principalmente desde Norteamérica se ha explorado el caso de la transgeneridad en la prensa inglesa y estadounidense (Baker, 2014; Zottola, 2018; Ferraresi, 2018). Las voces investigadoras señalan que las personas trans reciben un trato especial por parte de la prensa al ser relacionadas con escándalos sexuales y convertidas en objetos de burla debido a nociones normativas sobre la apariencia. A las mujeres además se les fetichiza como objetos sexuales y se les describe de manera colectiva y con términos negativos. Para el caso latinoamericano, se ha encontrado que la prensa de Colombia y Venezuela convierte 
en espectacular un tipo de corporalidad por medio de estereotipos discursivos y, al mismo tiempo, se apropia de ciertas subjetivadas trans para convertirlas en modelos de ciudadanía que se ajustan a las directrices del neoliberalismo (J.E. García León, 2021).

En relación con la representación de la discapacidad en la prensa, la mayoría de los estudios se enfocan en el contexto europeo o norteamericano (De Léséleuc, Athanasios y Marcellini, 2009; Solves Almela, 2013; Grue, 2015). Dichos trabajos resaltan que existe una modificación en el discurso público sobre los términos más adecuados para referirse a personas en condición de discapacidad; la prensa se ha visto obligada a cambiar su discurso cuando se refiere a esta comunidad; sin embargo, aún persisten representaciones que contribuyen a la discriminación y fetichización de dichos cuerpos. Por ejemplo, se ha encontrado que las mujeres deportistas discapacitadas son más sexualizadas que sus pares hombres quienes son infantilizados (De Léséleuc, Athanasios y Marcellini, 2009). En el caso latinoamericano, la mayoría de los estudios no asumen una perspectiva en la que se interseccione la discapacidad y la diversidad sexo-genérica. Los estudios tienden a analizar la representación de la discapacidad de manera general y han concluido que la agencia de las personas discapacitadas está limitada o es nula (Vergara-Heidke y Torres-Calderón, 2019).

Para el caso colombiano, existen pocos estudios sobre la discapacidad en la prensa y éstos se enfocan en la representación de las masculinidades cisgénero en condición de discapacidad y afectadas por el conflicto armado (por ejemplo, soldados lastimados por minas antipersonales) (Rutter-Jensen, 2018). Dichos estudios resaltan que, en algunas revistas colombianas, el cuerpo del soldado discapacitado tiende a ser construido de manera viril y heroica sin mencionar los aspectos sociales que lo han debilitado (Rutter-Jensen, 2018). Por otro lado, existen pocos trabajos en torno a la salud mental en la prensa colombiana, condiciones como la depresión, la bipolaridad o la esquizofrenia son ignorados por esta industria informativa. También se evidencia falta de conocimiento sobre este tipo de discapacidades, hecho que produce una representación limitada y sin diversidad de fuentes informativas. (Gutiérrez-Coba; Salgado-Cardona; García Perdomo y Guzmán-Rossini, 2017). No obstante, estos tipos de investigaciones no emplean como metodología un enfoque queer o la LQ/C. Además, a la fecha no se han encontrado investigaciones que aborden la 
representación de masculinidades y/o feminidades trans en condición de discapacidad, por ello la presente contribución es relevante y necesaria.

El estudio de la prensa es particularmente importante puesto que ésta desempeña un rol central en la consolidación colectiva de una nación. Ésta no sólo tiene como principal objetivo informar sobre hechos ocurridos en momentos específicos, sino que además construye el imaginario colectivo sobre la ciudadanía y su pertenencia a ella (Anderson, 1993). A esto se suma que la prensa es uno de los mediadores centrales entre el acontecer social y los individuos, ya que la población adquiere parte de los conocimientos sociales y políticos por este medio (van Dijk, 1990; Gutiérrez, 2010). En nuestro caso, nos preguntamos por la manera en que la prensa representa a las personas transgénero discapacitadas, es decir, buscamos responder al siguiente interrogante: ¿Cómo se construye discursivamente la transgeneridad en relación con la discapacidad? Para responder, hemos elegido la noticia Ammarantha Wass: activista, trans y ciega publicada en línea por el periódico El Espectador. Este diario cuenta con un tiraje de 50000 ejemplares de lunes a sábado y de 150000 los domingos, y es el segundo diario más consultado en internet en el país (Rivera, 2013, p. 65). Para el año 2015, la versión impresa semanal de El Espectador era consultada por 253325 personas mientras que al portal web de este periódico accedían 1463502 visitantes (El Tiempo, 2015). Para este mismo año, el sitio web del periódico se posicionaba en el puesto 18 de los sitios más visitados en Colombia según la subsidiaria de Amazon, Alexa Internet Inc. Además, dicho diario pertenece al Grupo Económico Santo Domingo, una de las instituciones financieras de mayor trayectoria y poder en Colombia.

La nota periodística seleccionada fue publicada el 19 de diciembre de 2017 en la sección Noticias Nacionales. Dicha nota generó un considerable impacto mediático, pues fue reproducida en diferentes medios colombianos. Ammarantha, la mujer trans discapacitada protagonista de la noticia, fue entrevistada por algunas estaciones de radio luego de la aparición del artículo ${ }^{10}$. Discursivamente, esta noticia se caracteriza por ser multimodal; es

\footnotetext{
${ }^{10} \mathrm{La}$ aparición de Ammarantha en la industria mediática colombiana forma parte del auge global de la representación trans (J.E. García León, 2019; Gossett et al., 2017). Otras mujeres trans colombianas con importante aparición mediática son María Luisa Fuentes, protagonista del documental Señorita María, la falda
} 
decir, existen distintos modos semióticos para presentar y construir la información. Uno de ellos es el texto de la noticia en sí mismo que ha sido escrito por una periodista y se acompaña de fotografías de Ammarantha, otra modalidad discursiva. Además, la noticia posee un video en donde vemos a la protagonista narrando una serie de experiencias y reflexiones sobre lo que implica ser mujer trans en condición de discapacidad (imagen 1). Este video se ubica en medio de la noticia y hace parte de Sin Clóset, un espacio del periódico El Espectador dedicado a la diversidad sexual. Dicho espacio posee una sección dentro del portal web de este diario y parte de su contenido puede ser encontrado en el canal de YouTube del periódico. Por lo tanto, la noticia es propia del periodismo audiovisual digital que se caracteriza por ser marcadamente multimodal y multimedial (Deuze, 2003; Hiippala, 2017). Esta característica genera unos efectos importantes en la audiencia; pues ésta debe elegir, por ejemplo, entre ver o no el audiovisual además de leer el texto escrito. Adicionalmente, el periodismo audiovisual digital lleva a enfrentarse a modos de interpretación distintos, pues mientras la noticia escrita involucra una lectura espacial de izquierda a derecha y de arriba abajo, la presencia de un video produce que la audiencia se enfrente a un texto propiamente audiovisual donde los marcadores de interpretación son otros (tomas, cuadros, enfoques, perspectivas, tiempo, etcétera).

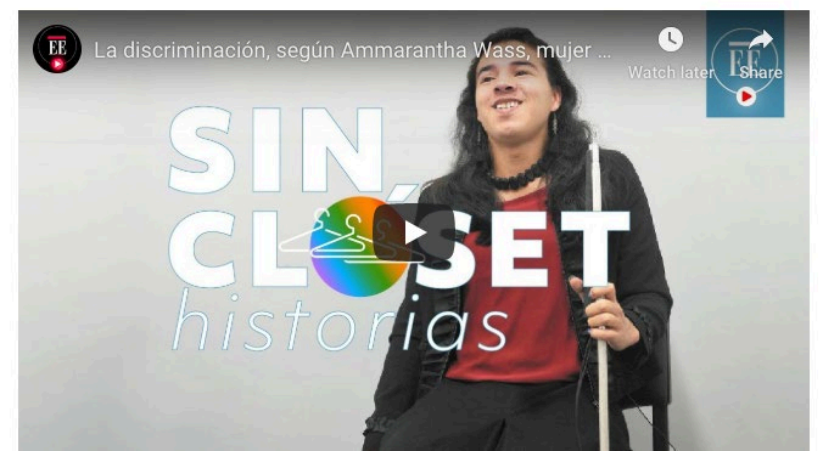

Imagen 1

En términos discursivo-textuales, la nota analizada se estructura a partir de dos macroestructuras o macroproposiciones que se desarrollan en el texto. La primera ocupa los cinco primeros párrafos de la noticia y termina justo cuando aparece el video. Ésta se caracteriza porque en ella prima la voz de la periodista encargada de la nota, ya que se cita

de la Montaña (2017) y Endry Cardeño, actriz de telenovelas y protagonista del filme Cheila, una casa pa' maita (2010). 
sólo una vez el discurso de Ammarantha. La segunda estructura inicia justo después de la aparición del video y, por el contrario, posee varias citas directas de Ammarantha, es un poco más corta y cierra la noticia. La primera macroestructura nos presenta la vida de esta mujer trans ciega, a través de mencionar a qué se dedica (por ejemplo, estudiante de lenguas extranjeras y activista) y contarnos sobre el inicio de su transición de género. Por su parte, la segunda estructura nos muestra, en voz de la protagonista, qué implica ser una mujer trans en condición de discapacidad y la manera política en que ella ha asumido su transición. Aunque en esta segunda parte Ammarantha es la fuente central, la información que se cita pasó por un proceso de selección.

Los resultados de este estudio de caso evidencian que ya no asistimos a la representación objetivizante y estereotipada de la mujer trans. Por el contrario, la actual representación se construye desde lo que aquí denominamos interseccionalidad acrítica. Ésta se caracteriza, primero, por presentar la transgeneridad como articulada a otros factores como la clase y la discapacidad y, segundo, por construir un discurso donde prima la individualización del devenir trans discapacitado y el ocultamiento de las causas y agentes productores del debilitamiento, así como la discriminación y la precarización de estas subjetividades. Este estudio de caso, por lo tanto, no sólo buscaba ilustrar la importancia de vincular la LQ/C con los estudios (críticos) de discapacidad, sino además responder a las siguientes preguntas: ¿Qué estrategias discursivas utiliza el periodismo audiovisual digital al momento de representar mujeres trans en condición de discapacidad? Y ¿Cuáles son y cómo se construyen lingüística y discursivamente las implicaciones políticas de dicha representación?

Como se ha sostenido, son muy pocos los artículos de prensa donde se retrata la vida de una persona trans discapacitada. Sin embargo, la prensa colombiana sí concibe a la transgeneridad como digna de representación. Especialmente en los últimos años, las notas que se refieren a este tema han proliferado. Aunque en algunos artículos de prensa todavía persiste la construcción de la subjetividad trans por medio de estereotipos (por ejemplo, la idea de una mujer atrapada en el cuerpo de un hombre), existe un cambio significativo en la manera en que se describe el devenir trans. Los periódicos reconocen la importancia de mencionar las interseccionalidades que afectan a estas personas (J.E. García León, 2021). De 
esta manera, en la nota de El Espectador, la interseccionalidad se manifiesta desde el título de la noticia a través de los términos "activista", "trans" y "ciega". A esto se suma, la descripción de su profesión, los previos y actuales empleos que ha ejercido, los lugares donde estudia y reside, su activismo, así como los grupos comunitarios a los que Ammarantha pertenece. Además, la noticia se enfoca menos en su cuerpo y evita un uso ambiguo del lenguaje para referirse a ella, es decir, respeta los nombres y pronombres elegidos por la persona representada. La nominación en la representación es un elemento central, debido a que, ésta le permite a la audiencia conocer quiénes son los actores representados, esto es, permite activar un conjunto de ideas relacionadas con los hechos y las propiedades del referente (Pardo, 2005). Como se observa en (1) y (2), la construcción discursiva de la transexualidad en la noticia se hace a través de la feminidad:

(1) Sin embargo, ella prefiere los días en el barrio Santa Fe, de Bogotá, donde trabaja con la organización Cuerpos en Resistencia para dignificar a las trabajadoras sexuales... (énfasis agregado).

(2) Desde que cambió su identidad de género, los hombres de su barrio también la han acosado en la calle e incluso le han ofrecido plata por sexo... (énfasis agregado).

A pesar de que se realiza una selección de pronombres que respeta la identidad de género de Ammarantha, el artículo presenta un marcado uso de elementos de cohesión que contribuyen a mantener una idea binaria frente a la persona representada. Las ideas de la primera macroestructura siempre se enlazan a través de conjunciones adversativas y locuciones preposicionales como "pero", "sin embargo", "aunque", "pese a". Esto se evidencia claramente en (3) y (4) en donde se produce la idea de que el actor social representado no posee una única identidad; esto es, se construye al agente como un sujeto que genera expectativas que parecen no cumplirse. Habría que cuestionar el uso reiterativo de esta estrategia lingüístico-discursiva: ¿ésta se emplea constantemente por el hecho de que Ammarantha es una mujer trans? Es decir, ¿se extrapola su identidad de género a otros aspectos de su vida, reivindicando nociones binarias frente a la identidad (por ejemplo, 
hombre / mujer; estudiante de sociales / estudiante de lenguas; trabajo tradicional / trabajo activista)?

(3) En las mañanas recibe clases de Lenguas Extranjeras en la Universidad Pedagógica, pero quien apenas la conoce cree que es de la carrera de Sociales. (énfasis agregado)

(4) Tenía un contrato indefinido, después de que a los 17 años iniciara sus prácticas de tecnología en Gestión de Mercados en el Sena... Sin embargo, ella prefiere los días en el barrio Santa Fe, de Bogotá, donde trabaja con la organización Cuerpos en Resistencia (énfasis agregado).

Por otro lado, un elemento que se debe resaltar es que se cita a Ammarantha como fuente de información directa, permitiendo que la audiencia comprenda sus vivencias y dificultades desde la experiencia de la protagonista. Estudios previos sobre la representación trans señalan que la prensa utiliza pocas fuentes de información y, cuando lo hace, son principalmente institucionales (por ejemplo, legisladores y profesionales de la salud) (Colette, 2014; J. E. García León, 2021). Por lo general, estas fuentes conciben la transexualidad desde perspectivas limitadas y basadas en el binarismo de género. Además, describen la transgeneridad como patológica y problemática para los gobiernos responsables de proteger a dicha comunidad. En la noticia, por el contrario, la voz de Ammarantha funciona como denuncia y ejemplo del activismo trans que ella realiza:

(5) Hacer el tránsito también le ha mostrado otras clases de discriminaciones. "A mí por ciega me sobreestiman y me admiran por cosas estúpidas como cruzar una calle. Pero el ser trans ya tiene todo un estereotipo de la 'pervertida', 'puta' o que 'va contra la naturaleza"', afirma.

Adicionalmente, la noticia no se enfoca en representar los cambios corporales de la protagonista. Brevemente se menciona la selección de vestuario que prefiere la activista trans y no se centra en describir cómo se maquilla ni cuándo lo hace. Esto es fundamental en tanto que muestra la transexualidad no como algo que se adquiere y se retira, sino como la 
identidad de género elegida por la persona representada. De este modo, la caracterización que se realiza de Ammarantha en la nota de El Espectador podría considerarse como positiva, ya que se aleja de las narrativas dominantes sobre la representación trans donde se les representaba como monstruosas, violentas, abyectas y engañadoras, además de no tener agenciamiento discursivo (Halberstam, 2005; Serano, 2007; Ryan, 2009; J.E. García León, 2021).

Sin embargo, el marcado uso de la estrategia de individualización del devenir trans discapacitado es problemático en tanto que contribuye a ocultar las causas y agentes productores del debilitamiento, la discriminación y la precarización de estas subjetividades. Esto se evidencia a través de diferentes elementos. Primero, se oculta el tiempo trans discapacitado (trans-crip time). Revelarlo implicaría mostrar las políticas y los regímenes cisheteronormativos y capacitistas que oprimen a las personas trans discapacitadas en el país. Es importante recordar que el tiempo discapacitado es aquel que se refiere a las temporalidades adicionales que necesitan las personas discapacitadas para realizar sus actividades diarias. Se puede concebir al tiempo trans discapacitado como el tiempo adicional que las personas necesitan para a) aprender acerca de los códigos de la sexualidad y las opciones médicas disponibles, b) adquirir trabajos donde no las discriminen, c) adquirir documentos de identidad acordes a su identidad de género, entre muchos otros (Baril, 2016). Estos tiempos son impuestos a las personas trans en las sociedades cisnormativas y podrían eliminarse si las instituciones sociales se adaptaran mejor a sus necesidades. En el caso de Ammarantha, el tiempo trans viene acompañado del tiempo discapacitado, el cual es producto de las sociedades cisnormativas y capacitistas. Por ejemplo, al describir su tránsito de género no se mencionan las trabas que impone el Estado colombiano para el acceso a documentos legales ni las razones por las cuales uno de sus empleos no es remunerado (6) y (7):

(6) Ammarantha inició su tránsito el año pasado y eso le costó que la echaran de su hogar, ha sobrevivido gracias al trabajo doméstico y al reciclaje.

(7) En las mañanas recibe clases de Lenguas Extranjeras en la Universidad Pedagógica, pero quien apenas la conoce cree que es de la carrera de Sociales. Y 
en las tardes trabaja por los derechos humanos, aunque no sea un empleo remunerado (énfasis agregado).

En la nota, los tiempos se omiten totalmente y aunque el artículo "denuncia" la exclusión por la que pasa esta mujer, los factores causantes de ésta, así como los actores que ejercen violencia simbólica y física no aparecen explícitos en la noticia. La exclusión y la inclusión de otros actores sociales e intertextos dan cuenta de los intereses de quien elabora el discurso. Siguiendo a Neyla Pardo (2005), cuando la exclusión discursiva es total, por ejemplo, no existe forma de rastrear los actores ni sus acciones; cuando ésta es parcial, los actores y sus acciones están en el trasfondo del discurso y casi siempre su objetivo es restarle importancia a un actor determinado. De esta manera, en la noticia sobre Ammarantha la "denuncia" de las precariedades que afrontan las personas trans discapacitadas se construye por medio de exclusiones parciales (8) y (9):

(8) Su vida es el trabajo comunitario y la lucha contra las desigualdades sociales, a las que ha tenido que enfrentar desde distintos frentes.

(9) Desde que cambió su identidad de género, los hombres de su barrio también la han acosado en la calle e incluso le han ofrecido plata por sexo.

Como se observa en (8) se hace referencia a las desigualdades sociales; sin embargo, no se menciona quiénes son los causantes directos, es decir, los actores y sus acciones. La desigualdad aparece como dada, natural y ahistórica, esto es, no es posible rastrear en la noticia cómo la colonialidad del género implementó el binarismo sexual en las sociedades latinoamericanas, generando que a las personas trans se les negara el derecho a existir. Recuérdese que las normas de género establecen qué vidas son dignas de ser vividas y cuáles no. La materialización de esta norma se refleja en el acceso a diferentes servicios sociales, a poder ejercer la ciudadanía y a no ser violentado física ni simbólicamente por aquellos a quienes la norma sí considera como parte de la ciudadanía. Adicionalmente, en (9) la mención de los hombres que acosan a Ammarantha oculta la caracterización total de este grupo, es decir, hombres cisgénero heterosexuales principalmente. Por medio de esta omisión de la información se mantiene oculto el constante debilitamiento de las subjetividades trans, 
pues se individualiza su lucha y no se cuestionan las estructuras que han creado dichas opresiones.

En cuanto a la discapacidad, de nuevo no se explicitan los actores y discursos que precarizan a las personas en esta condición. Por el contrario, el retrato que se realiza de Ammarantha se fundamenta en un tropo discursivo común en la representación de las personas discapacitadas, la inspiración pornográfica. Ésta consiste en construir a las personas discapacitadas como individuos que superan obstáculos o dificultades de manera heroica a pesar de que éstas son usualmente tareas de la vida cotidiana (por ejemplo, tomar el bus, vestirse) (Clare, 1999). Esta heroización conduce a que las personas no discapacitadas se sientan inspiradas por estas experiencias, reivindicando el capacitismo. En el caso aquí analizado, la inspiración pornográfica se fundamenta en relacionar el activismo y la discapacidad desde una interseccionalidad acrítica. La nota construye a Ammarantha como una luchadora contra la discriminación "a pesar de" ser ciega. Sin embargo, el ente contra el que lucha, la discriminación, siempre es presentado de manera abstracta como podemos notar en los siguientes dos ejemplos:

(10) Su vida es el trabajo comunitario y la lucha contra las desigualdades sociales, a las que ha tenido que enfrentar desde distintos frentes.

(11) Ammarantha inició su tránsito el año pasado y eso le costó que la echaran de su hogar; ha sobrevivido gracias al trabajo doméstico y al reciclaje.

En (10) no es posible determinar quiénes producen dichas desigualdades sociales, sólo sabemos que Ammarantha las combate. En (11) el hecho de que Ammarantha sea una mujer trans es presentado como la causa de que abandonara su hogar, no la transfobia presente en su familia; además, se convierte en heroína a la protagonista a través de la selección de términos como "sobrevivir". Por lo tanto, aunque se relacionan diversos elementos (discapacidad, activismo, tránsito de género) estos no se trasladan al plano político y social, se presentan como propios del individuo, generando una interseccionalidad acrítica. 
El marcado énfasis en la individualización genera efectos contraproducentes en dos sentidos. Por un lado, se oculta la responsabilidad de otros actores y, por otro, se refuerzan las lógicas neoliberales actuales en donde el sujeto se considera como un gestor propio de su vida sin constricciones sociales. Recuérdese que el ciudadano neoliberal es aquel que puede contribuir al avance de su nación a través de cultivar un espíritu emprendedor y de lucha, dentro del mercado económico actual, que se caracteriza por su autorregulación y por evitar la intervención del Estado (Irving, 2013). En la primera estructura de la nota, se presenta a Ammarantha en relación con el empleo; no obstante, no se discuten o retratan las razones por las cuales uno de sus trabajos no es remunerado:

(12) Y en las tardes trabaja por los derechos humanos, aunque no sea un empleo remunerado.

Sin embargo y de manera limitada, el video y la segunda macroestructura de la nota periodística permiten que la audiencia comprenda algunos aspectos sociales y políticos que atraviesan la discapacidad y la transgeneridad. Así, la voz de Ammarantha aparece directamente en la noticia por medio de citas directas de su discurso o por el uso de la técnica de personas parlantes. Estas dos estrategias discursivo-visuales sirven para que la protagonista narre sus experiencias como mujer trans ciega. El video de 2 minutos y 19 segundos de duración se construye mayoritariamente a través de la técnica mencionada, esto es, la audiencia escucha y ve a Ammarantha. Sin embargo, no existe rastro de las preguntas o instrucciones que posiblemente está dando la periodista (imagen 2). Cabe mencionar que este mecanismo es el más utilizado en las producciones documentales sobre mujeres trans en Colombia y permite que la audiencia se acerque a las realidades de estas personas que aparecen en la pantalla, como ha sucedido con un gran número de documentales (trans) feministas (Horak, 2018; J.E. García León, 2019). 


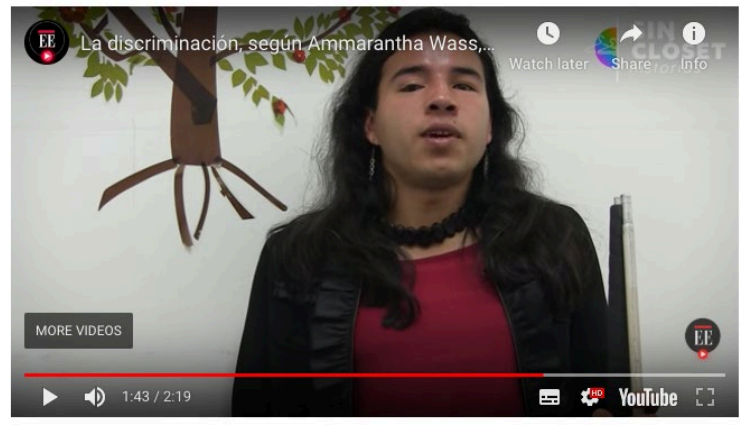

Imagen 2

Incluir la voz directa de Ammarantha permite entender al menos tres aspectos que no aparecen cuando prima la voz de la periodista. Primero, existe una posición política sobre la transgeneridad; ésta se refleja en las afirmaciones que la protagonista realiza sobre la hormonización y su relación con estándares normativos de belleza. Para Ammarantha, dicha práctica puede terminar reivindicando modelos de feminidad hegemónicos. Este hecho, sin embargo, sólo aparece en el video y no en la nota misma, la audiencia que no acceda al texto audiovisual podría pasarlo por alto. Su crítica a los patrones dominantes de feminidad es importante en tanto que cuestiona la idea errada de que no existen personas trans que viven felizmente sin modificaciones corporales. Según los discursos dominantes que promueven los medios, las personas trans sólo tienen vidas satisfactorias si toman hormonas, pasan por cirugías o se hiperfeminizan (masculinizan). Estos discursos, a los que se opone Amaranta, reproducen las normas cisgénero. En segundo lugar, Ammarantha no sólo deconstruye el tropo de la inspiración pornográfica, sino que además lo vincula a los tropos sobre las mujeres trans como se refleja en (13).

(13) "A mí por ciega me sobreestiman y me admiran por cosas estúpidas como cruzar una calle. Pero el ser trans ya tiene todo un estereotipo de la 'pervertida', 'puta' o que "va contra la naturaleza", afirma.

(14) Ammarantha se travistió por primera vez en una marcha antiteletón. Sus compañeros de lucha, con alguna discapacidad, se molestaron. "Para eso había una marcha gay", dijeron con repudio algunos. "Dentro de la población con discapacidad también hay unas hipermasculinidades. El machismo está en la sociedad grande y en las poblaciones pequeñas", explica Wass. 
Por último, la voz de Ammarantha denuncia no sólo a los actores que la discriminan, sino que adicionalmente explica la forma en que los diferentes sistemas de opresión se constituyen y reproducen como se refleja en (14). Por lo tanto, la experiencia encarnada de Ammarantha permite entender la interseccionalidad entre discapacidad y transgeneridad de manera compleja.

\section{Conclusión}

En el presente trabajo se expusieron los principales postulados de la LQ y se examinaron sus potencialidades para el caso latinoamericano de habla hispana principalmente. En particular, se resaltaron sus vínculos con los estudios críticos de la discapacidad. Además, se presentaron los resultados de un estudio de caso de la representación de una mujer trans discapacitada en la prensa escrita y audiovisual colombiana. Del estudio se encontró que la discapacidad y la transgeneridad son asumidos desde una interseccionalidad acrítica que individualiza el devenir trans discapacitado y oculta las causas y agentes productores del debilitamiento, la discriminación y la precarización de estas subjetividades. De este modo, en este trabajo se propuso una $\mathrm{LQ} / \mathrm{C}$ interseccional, crítica y decolonial cuyo objetivo es comprender la construcción discursiva de la cisheteronormatividad en relación con la discapacidad y el capacitismo.

Para terminar, cabe mencionar dos aspectos sobre la representación de las subjetividades trans discapacitadas. Primero, un análisis desde la LQ/C requiere que se exploren recursos teóricos (por ejemplo, discapacitado, debilidad, etcétera) propios de los ECD, pues éstos nos permiten comprender mejor cómo funcionan los discursos acerca de la diversidad, ya sea esta corporal, de género o ambas. Adicionalmente, se debe reflexionar sobre la falta de discursos mediáticos producidos por personas trans discapacitadas que representen sus realidades. Al igual que en los documentales, las personas (trans) discapacitadas continúan siendo, mayoritariamente, objeto de representación y no productoras de textos audiovisuales o escritos. Generar representaciones propias desde la discapacidad (trans) podría contribuir al desmantelamiento de, por ejemplo, estrategias discursivas como la inspiración pornográfica. 
Esto, además, implicaría crear otras notas periodísticas donde se cuestione la colonialidad del género. La noticia aquí analizada no se compromete a denunciar la discriminación racial ni de clase. Por ello, el llamado es a producir y circular discursos alternativos sobre la transgeneridad y la discapacidad que nos ofrezcan nuevas formas de entender esta(s) subjetividad(es).

\section{Financiación}

Este trabajo fue apoyado, en parte, por fondos provenientes de The University of North Carolina at Charlotte

\section{Agradecimientos}

Agradecemos a las personas que evaluaron este trabajo por los excelentes comentarios y a Anastasia Ramjag por la revisión del resumen en inglés.

\section{Referencias bibliográficas}

Anderson, Benedict. (1993). Comunidades imaginadas. Reflexiones sobre el origen y la difusión del nacionalismo (Eduardo L. Suárez, Trad.) México: Fondo de Cultura Económica.

Antebi, Susan. (2009). Carnal Inscriptions: Spanish American Narratives of Corporeal Difference and Disability. New York: Palgrave Macmillan.

Antebi, Susan y Jörgensen, Beth E. (Eds.) (2016). Libre Acceso. Latin American Literature and Film through Disability Studies. New York: SUNY Press.

Baker, Paul. (2014). Bad Wigs and Screaming Mimis: Using Corpus-Assisted Techniques to Carry out Critical Discourse Analysis of the Representation of Trans People in the British Press. En Chris Hart y Piotr Cap (Eds.), Contemporary Critical Discourse Studies (pp. 211-235). London: Bloomsbury. 
Baril, Alexandre. (2016). "Doctor, Am I an Anglophone Trapped in a Francophone Body?" An Intersectional Analysis of "Trans-Crip-t Time" in Ableist, Cisnormative, Anglonormative Societies. Journal of Literary \& Cultural Disability Studies, 10(2), 155-72. Recuperado de https://www.muse.jhu.edu/article/625071

Borba, Rodrigo. (2015). Linguística queer: uma perspectiva pós-identitária para os estudos da linguagem. Revista Entrelinhas, 9(1), 91-107. doi: https://doi.org/10.4013/10378

Borba, Rodrigo y Milani, Tommaso. (2019). Colonial Intertexts: Discourses, Bodies and Stranger Fetishism in the Brazilian Media. Discourse, Context \& Media, 30, 1-11. doi: https://doi.org/10.1016/j.dcm.2019.01.003

Butler, Judith. (1990). Gender Trouble. New York, London: Routledge.

Campos Pinto, Paula. (2011). Between the Lines: A Critical Discourse Analysis of Disability Policy in Portugal. Disability Studies Quarterly, 31(3), doi: http://dx.doi.org/10.18061/dsq.v31i3.1678

Clare, Eli. (1999). Exile and Pride. Disability, Queerness and Liberation. Cambridge: South End Press.

Clare, Eli. (2017). Brilliant Imperfection: Grappling with Cure. Durham, London: Duke University Press.

Connell, Raewyn. (2011). Southern Bodies and Disability: Re-thinking Concepts. Third World Quarterly, 32(8), 1369-1381. doi: https://doi.org/10.1080/01436597.2011.614799

Colette, Jamie. (2014). Who Defines Gender Diversity? Sourcing Routines and Representation in Mainstream U.S. News Stories About Transgenderism. International 
Journal of Transgenderism, 15, 115-128. doi: https://doi.org/10.1080/15532739.2014.946195

Colombia Diversa. (2017). La discriminación, una guerra que no termina. Informe de Derechos Humanos de Personas Lesbianas, Gays, Bisexuales y Trans en Colombia 2017. Bogotá: Colombia Diversa y Caribe Afirmativo. Recuperado de https://colombiadiversa.org/colombiadiversa2016/wp-content/uploads/2018/07/A0450_OS_baja-Informe-DDH.pdf

Correa-Montoya, Lucas y Castro-Martínez, Marta Catalina. (2016). Disability and Social Inclusion in Colombia. Saldarriaga-Concha Foundation. Alternative Report to the Committee on the Rights of Persons with Disabilities. Bogota: Saldarriaga-Concha Foundation Press.

Crenshaw, Kimberle. (1991). Mapping the Margins: Intersectionality, Identity Politics, and Violence against Women of Color. Stanford Law Review 43(6), 1241-99. doi: $10.2307 / 1229039$

De Léséleuc, Eric; Athanasios, Pappous y Marcellini, Anne. (2009). La cobertura mediática de las mujeres deportistas con discapacidad. Análisis de la prensa diaria de cuatro países europeos durante los Juegos Paralímpicos de Sidney 2000. Apunts Educación Física $\quad y \quad$ Deportes, 3(97), 80-88. Recuperado de https://www.raco.cat/index.php/ApuntsEFD/article/view/300101/389570

Derrida, Jacques. (1976). Of Grammatology. Baltimore: John Hopkins University Press.

Deuze, Mark. (2003). The Web and its Journalisms: Considering the Consequences of Different Types of Newsmedia Online. New Media \& Society, 5(2), 203-230. doi: https://doi.org/10.1177/1461444803005002004 
El Tiempo. (6 junio 2015). Audiencia de EL TIEMPO Continúa en crecimiento. Recuperado de https://www.eltiempo.com/archivo/documento/CMS-15907306

Epps, Brad. (2008). Retos, riesgos, pautas y promesas de la Teoría Queer. Revista Iberoamericana, LXXIV(225), 897-920.

Espinosa, Juan Manuel. (2016). The Blur of Imagination: Asperger's Syndrome and One Hundred Years of Solitude. En Susan Antebi y Beth E. Jörgensen (Eds.), Libre Acceso. Latin American Literature and Film through Disability Studies (pp. 245-58). New York: SUNY Press.

Fairclough, Norman. (2003). Analysing Discourse. Textual Analysis for Social Research. New York: Routledge.

Falconí, Diego. (2014). Queer/Cuir/Cuy(r) En América Latina. Accidentes y malos entendidos en la narrativa de Ena Lucía Portela. Mitologías hoy: Revista de pensamiento, crítica y estudios literarios latinoamericanos, 10, 95-113.

Ferraresi, Adriano. (2018). Who Writes the Story Matters: Transgender Identity Through the Lens of Citizen Journalism. En Giuseppe Balirano y Oriana Palusci (Eds.), Miss Man? Languaging Gendered Bodies (pp. 190-215). Newcastle: Cambridge Scholars.

Foucault, Michel. (1997). Historia de la sexualidad 1. La voluntad del saber (Ulises Guinazú, Trad.) España: Siglo XXI editores.

La Fountain-Stokes, Lawrence. (2010). Translocas: Migration, Homosexuality, and Transvestism in Recent Puerto Rican Performance. E-misférica. Recuperado http://archive.hemisphericinstitute.org/hemi/en/e-misferica-81/lafountain

Fraser, Benjamin. (2013). Disability Studies and Spanish Culture Films, Novels, the Comic and the Public Exhibition. Liverpool: Liverpool University Press. 
Gallop, Jane. (2019). Sexuality, Disability, and Aging. Queer Temporalities of the Phallus. Durham: Duke University Press.

García León, David Leonardo. (2018a). La representación de la(s) masculinidad(es) en la industria cultural colombiana. Las politicas de género en SoHo y sus escritores (Tesis Doctoral). University of Ottawa. Recuperado de https://ruor.uottawa.ca/handle/10393/37755

García León, David Leonardo. (2021). Cuerpo y discapacidad en el cine colombiano reciente. El caso de Porfirio (2019) de Alejandro Landes. Bulletin of Hispanic Studies, 98(5), 507-529. doi: https://doi.org/10.3828/bhs.2021.29

García León, Javier Enrique y García León, David Leonardo. (2017). Sujetos intersexuales y matriz heterosexual: Los cuerpos que le importan a la jurisprudencia colombiana; Una lectura queer. Latin American Research Review, 52(1), 124-137. doi: https://doi.org/http://doi.org/10.25222/larr.77

García León, Javier Enrique. (2019). Documentando la producción audiovisual transloca colombiana. Apuntes críticos sobre la representación trans. Canadian Journal of Latin American and Caribbean Studies, 44(3), 261-280. doi: https://doi.org/10.1080/08263663.2019.1634880

García León, Javier Enrique. (2021). Espectáculo, normalización y representaciones otras. Las personas transgénero en la prensa y el cine de Colombia y Venezuela. Berlín: Peter Lang.

Garland-Thomson, Rosemarie. (1997). Extraordinary Bodies. Figuring Physical Disability in American Culture and Literature. New York: Columbia University Press.

Garland-Thomson, Rosemarie. (2009). Staring: How We Look. Oxford: Oxford University Press. 
Gossett, Reina; Stanley, Eric y Burton, Johanna. (Eds.) (2017). Trap Door. Trans Cultural Production and the Politics of Visibility. Cambridge, London: MIT Press.

Grue, Jan. (2011). Discourse analysis and disability: Some topics and issues. Discourse \& Society, 22(5), 532-546. doi: https://doi.org/10.1177/0957926511405572

Grue, Jan. (2015). Disability and Discourse Studies. Farnhan: Ashgate Publishing Limited.

Gutiérrez-Coba, Liliana; Salgado-Cardona, Andrea; García Perdomo, Víctor y GuzmánRossini, Yahira. (2017). Cubrimiento de la salud mental en la prensa colombiana, un aporte aún en construcción. Revista Latina de Comunicación Social, (72), 114-28. doi: https://doi.org/10.4185/RLCS-2017-1156

Gutiérrez, Silvia. (2010). Discurso periodístico: una propuesta analítica. Comunicación y sociedad, 7(14), 169-198. doi: https://doi.org/10.32870/cys.v0i14.1285

Guzmán, Paco y Platero, Raquel (Lucas). (2012). Passing, enmascaramiento y estrategias identitarias: diversidades funcionales y sexualidades no-normativas. En Lucas Platero (Ed.), Intersecciones: cuerpos y sexualidades en la encrucijada. Temas contemporáneos (pp. 125-158). Madrid: Ediciones Bellaterra. Recuperado de https://core.ac.uk/download/pdf/36118599.pdf

Halberstam, Jack. (Judith). (2005). In a Queer Time and Place. Transgender Bodies, Subcultural Lives. New York: New York University Press.

Hiippala, Tuomu. (2017). The Multimodality of Digital Longform Journalism. Digital Journalism, 5(4), 420-442. doi: https://doi.org/10.1080/21670811.2016.1169197

Horak, Laura. (2018). Visibility and Vulnerability: Translatina world-making in The Salt Mines and Wildness. En Anu Koivunen, Katariina Kyrölä and Ingrid Ryberg (Eds.), The Power of Vulnerability: Mobilising affect in feminist, queer and anti-racist media 
cultures (pp. 95-115). Manchester: Manchester University Press. Recuperado de https://www.manchesteropenhive.com/view/9781526133113/9781526133113.00012. $\mathrm{xml}$

Irving, Dan. (2013). Normalized Transgressions: Legitimizing the Transsexual Body as Productive. En Susan Stryker y Aren Aizura (Eds.), The Transgender Studies Reader 2 (pp. 15-29). New York: Routledge.

Kafer, Alison. (2013). Feminist Queer Crip. Bloomington: Indiana University Press.

Leap, William. (2015). Queer Linguistics as Critical Discourse Analysis. En Deborah Tannen, Heidi E. Hamilton, y Deborah Schiffrin (Eds.), The Handbook of Discourse Analysis (pp. 661-680). Oxford: JohnWiley \& Sons.

Levon, Erez. (2015). Integrating Intersectionality in Language, Gender, and Sexuality Research. Language and Linguistics Compass, 9(7), 295-308. doi: https://doi.org/10.1111/lnc3.12147

Lau, Héliton Diego y Borba, Rodrigo. (2019). Conhecendo a linguística queer: entrevista com Rodrigo Borba. Revista X, 14(4), 8-19. doi: http://dx.doi.org/10.5380/rvx.v14i4.66070

Lewis, Elizabeth Sara. (2013). Queer Subversion or Heteronormative Reinforcement? Linguistic Performativity in Identity Constructions of a Young Bisexual-Identified Brazilian LGBT Activist. En Kathleen O’Mara y Liz. Morrish (Eds.), Queering Paradigms III. Queer Impact and Practices (pp. 200-235). Berlin: Peter Lang.

Lewis, Elizabeth Sara. (2018). Do "léxico gay" à Linguística Queer: desestabilizando a norma homossexual oculta nas Teorias Queer. Estudos Linguísticos, 47(3), 675-690. doi: $10.21165 /$ el.v47i3.2049 
Lewis, Elizabeth Sara; Borba, Rodrigo; Fabrício, Branca y Souza de Pinto, Diana. (Eds.) (2014). Queering Paradigms IV. South-North Dialogues on Queer Epistemologies, Embodiments and Activisms. Berlin: Peter Lang.

Lewis, Vek. (2010). Crossing Sex and Gender in Latin America. New York: Palgrave Macmillan.

Lugones, María. (2007). Heterosexualism and the Colonial. Modern Gender System. Hypatia. A Journal of Feminist Philosophy, 22(1), 186-209. doi: https://doi.org/10.1111/j.1527-2001.2007.tb01156.x

Lugones, María. (2008). Colonialidad y Género. Tabula Rasa, 9, 73-101. Recuperado de https://www.revistatabularasa.org/numero-9/05lugones.pdf

Maués Corrêa, Júlia Antônia y da Silva Cruz, Marcos. (2019). Entre machos e discretos: discursos, identidades homoeróticas masculinas $\mathrm{e}(\mathrm{m})$ aplicativos de relacionamento. Revista Heterotópica, 1(2), 108-135. doi: https://doi.org/10.14393/HTP-v1n2-201950080

Moreno Sánchez, José Javier. (2018). Lingüística Queer y Análisis Crítico del Discurso. Aplicaciones en el Ámbito Educativo. En Ernesto Cutillas Orgilés (Ed.), La Multiplicidad de Enfoques en Humanidades. Actas de las VIII Jornadas de Investigación de la Facultad de Filosofía y Letras de la Universidad de Alicante (Alicante, 3 y 4 de mayo de 2018) (pp. 53-59). Compobell. Recuperado de http://hdl.handle.net/10045/91598

Moreno Sánchez, José Javier. (2019). La carta robada. Un estudio sobre la (no)percepción de la heteronormatividad en el ámbito educativo. Discurso \& Sociedad, 13(4), 556-574. Recuperado de http://www.dissoc.org/ediciones/v13n04/DS13\%284\%29MorenoSanchez.pdf 
McRuer, Robert. (2006). Crip Theory. Cultural Signs of Queerness and Disability. New York, London: New York University Press.

McRuer, Robert. (2018). Crip Times. Disability, Globalization, and Resistance. New York: New York University Press.

Meekosha, Helen. (2011). Decolonising disability: Thinking and acting globally. Disability \& Society, 26(6), 667-682. doi: https://doi.org/10.1080/09687599.2011.602860

Milani, Tommaso. (2013a). Are 'Queers' Really ‘Queer'? Language, Identity and Same-Sex Desire in a South African Online Community. Discourse \& Society, 24(5), 615-33. doi: https://doi.org/10.1177/0957926513486168

Milani, Tommaso. (2013b). Expanding the Queer Linguistic scene: Multimodality, space and sexuality at a South African university. Journal of Language and Sexuality, 2(2), 206234. doi: https://doi.org/10.1075/j1s.2.2.02mil

Milani, Tommaso y Wolff, Brandon. (2015). Queer Skin, Straight Masks: Same-Sex Weddings and the Discursive Construction of Identities and Affects on a South African Website. Critical Arts: South-North Cultural and Media Studies, 29(2), 165-182. doi: https://doi.org/10.1080/02560046.2015.1039203

Motschenbacher, Heiko. (2010). Language, Gender and Sexual Identity. Poststructuralist Perspectives. Amsterdam, Philadelphia: John Benjamins Publishing Company.

Muñoz, José Esteban. (1999). Disidentifications. Queers of color and the performance of politics. University of Minnesota Press.

Pardo, Neyla. (2005). Representación de los actores armados en conflicto en la prensa colombiana. Forma y Función 18, 167-96. Recuperado de https://revistas.unal.edu.co/index.php/formayfuncion/article/view/17981/18868

$$
\text { Estudios de Género, 7, e560 e-ISSN 2395-9185 }
$$


Pardo Pedraza, Diana. (2017). The Amputated Body. Ghostly and Literal Presence. En Andrea Fanta Castro, Alejandro Herrero-Olaizola y Chloe Rutter-Jensen (Eds.), Territories of Conflict. Traversing Colombia through Cultural Studies (pp. 147-159). Rochester: University of Rochester Press.

Pereira Silva, Danillo; Ferreira de Melo, Iran y Gomes Freitas de Castro, Lorena. (Orgs.) (2017). Dissidências sexuais e de gênero nos estudos do discurso. Aracaju: Criação.

Puar, Jasbir. (2017). The Right to Maim. Debility, Capacity, Disability. Durham: Duke University Press.

Resende, Viviane de Melo. (2018). Decolonizing Critical Discourse Studies: for a Latin American Perspective. Critical Discourse Studies, 15(1), 1-17. doi: https://doi.org/10.1080/17405904.2018.1490654

Resende, Viviane de Melo. (Ed.) (2019). Decolonizar os estudos críticos do discurso. Campina: Pontes Editores.

Rivera, Claudia. (2013). Representaciones sociales de 'mujeres' lesbianas en prensa escrita de Colombia. Un análisis de la colonialidad de género y la heterosexualidad obligatoria. (Tesis de Maestría). Universidad Nacional de Colombia. Recuperado de https://repositorio.unal.edu.co/handle/unal/20634

Romañach, Javier y Lobato, Manuel. (2005). Diversidad funcional, nuevo término para la lucha por la dignidad en la diversidad del ser humano. Foro de Vida Independiente. Recuperado de http://forovidaindependiente.org/wpcontent/uploads/diversidad_funcional.pdf

Rutter-Jensen, Chloe. (2018). Fabricación de 'armas' o piernas: un análisis de la representación de cuerpos de soldados mutilados en el conflicto armado colombiano. 
Iberoamericana, 18(67), 161-178. doi: https://doi.org/10.18441/ibam.18.2018.67.161178

Ryan, Joelle. (2009). Reel Gender: Examining the Politics of Trans Images in Film and Media (Tesis Doctoral). Bowling Green State University. Recuperado de https://etd.ohiolink.edu/pg_10?0::NO:10:P10_ACCESSION_NUM:bgsu1245709749

Saussure, Ferdinand de. (1983). Course in General Linguistics (Roy Harris, Trad.) London: Duckworth.

Serano, Julia. (2007). Whipping Girl. A Transsexual Woman on Sexism and the Scapegoating of Feminity. Berkeley: Seal Press.

Shakespeare, Tom. (2000). Disabled sexuality: Toward rights and recognition. Sexuality and Disability, 18, 159-166. doi: https://doi.org/10.1023/A:1026409613684

Shildrick, Margrit. (2009). Dangerous Discourses of Disability, Subjectivity and Sexuality. London: Palgrave Macmillan UK. Recuperado de http://ink.springer.com/10.1057/9780230244641

Siebers, Tobin. (2010). Disability Aesthetics. Ann Arbor: University of Michigan Press.

Snyder, Sharon; Mitchell, David. (2001). Re-engaging the Body: Disability Studies and the Resistance to Embodiment. Public Culture, 13(3), 367-89.

Solves Almela, Josep. (2013). SOS Discapacidad. Los discursos de la discapacidad en los medios españoles. Discurso \& Sociedad, 7(1), 49-72.

Stamou, Anastasia; Alevriadou, Anastasia y Soufla, Fenia. (2016). Representations of Disability from the Perspective of People with Disabilities and Their Families: A Critical Discourse Analysis of Disability Groups on Facebook. Scandinavian Journal 
of Disability Research, 18(1), 1-16. doi: http://doi.org/10.1080/15017419.2014.962611

Van Dijk, Teun. (1990). La Noticia como discurso. Comprensión, estructura y producción de la información. Barcelona: Paidós.

Van Dijk, Teun. (1999). El Análisis Crítico del Discurso. Anthropos, 186, 23-36.

Valencia, Sayak. (2014). Teoría transfeminista para el análisis de la violencia machista y la reconstrucción no-violenta del tejido social en el México contemporáneo. Universitas Humanística, $\quad 78, \quad 65-88 . \quad$ Recuperado de http://www.scielo.org.co/pdf/unih/n78/n78a04.pdf

Vergara-Heidke, Adrián y Torres-Calderón, Gina. (2019). Representación de las personas con discapacidad en los anuncios publicitarios en Costa Rica: revisión desde el análisis multimodal. Logos: Revista de Lingüistica, Filosofía y Literatura, 29(1), 149-64. doi: https://doi.org/10.15443/RL2911

Wodak, Ruth. (2006). Critical Linguistics and Critical Discourse Analysis. En Jef Verschueren, Jan-Ola Östman y Eline. Versluys (Eds.), Handbook of Pragmatics (pp. 1-24). Amsterdam, Philadelphia: Jhon Benjamins. doi: https://doi.org/10.1075/hop.10.cri1

Zottola, Angela. (2018). Transgender Identity Labels in the British Press. A Corpus-Based Discourse Analysis. Journal of Language and Sexuality, 7(2), 237-262. doi: https://doi.org/10.1075/j1s.17017.zot 


\section{DAVID LEONARDO GARCÍA LÉON}

Es profesor asistente de español (Estudios Interculturales) en Maynooth University, Irlanda. Doctor en Español por la Universidad de Ottawa, magíster en Lingüística de la Universidad Nacional de Colombia, licenciado en Español e Inglés de la Universidad Pedagógica Nacional (Colombia). Sus áreas de investigación y publicación son la sociolingüística, el análisis crítico del discurso, la lingüística queer y los estudios culturales latinoamericanos y de medios con énfasis en masculinidades y teoría queer crip.

\section{JAVIER ENRIQUE GARCÍA LEÓN}

Es profesor asistente de lingüística hispánica en The University of North Carolina at Charlotte. Doctor en Español por la Universidad de Ottawa, magíster en Lingüística de la Universidad Nacional de Colombia, licenciado en Español e Inglés de la Universidad Pedagógica Nacional (Colombia). Sus áreas de trabajo son las lenguas en contacto, las actitudes y políticas lingüísticas, así como el análisis crítico de discurso, la lingüística queer y los estudios (LGBTQI+) latinoamericanos culturales y de medios. 